\title{
PRAGMATIC ATTITUDES AND SEMANTIC COMPETENCE
}

\author{
Maite Ezcurdia \\ Instituto de Investigaciones Filosóficas \\ Universidad Nacional Autónoma de México \\ maite@servidor.unam.mx
}

SUMMARY: In this paper I argue against the account Soames offers in Beyond Rigidity of the semantics and pragmatics of propositional attitude reports. I defend a particular constraint for identifying semantic content of phrases based on conditions for semantic competence, and argue that failure of substitutivity is an essential component of our competence conditions with propositional attitude predicates. Given that Soames's account makes no room for this, I conclude that he does not offer an adequate explanation of propositional attitude reports.

KEY WORDS: semantics, pragmatics, propositional attitude reports, competence, content

RESUMEN: En este trabajo argumento contra la explicación de la semántica y la pragmática de las adscripciones de actitudes proposicionales que Soames ofrece en Beyond Rigidity. Defiendo una restricción para la identificación del contenido semántico de las frases de un lenguaje basada en las condiciones de competencia semántica, y argumento que la falla de sustitutividad es un componente esencial de nuestras condiciones de competencia en los predicados de actitudes proposicionales. Dado que la explicación de Soames no respeta esta condición, concluyo que no es una explicación adecuada de las adscripciones de actitudes proposicionales.

PALABRAS CLAVE: semántica, pragmática, adscripciones de actitudes proposicionales, competencia, contenido

\section{Some Background}

In Beyond Rigidity (hereafter, BR) Soames presents a defence of a view according to which names are directly referential or Millian and propositions are Russellian. ${ }^{1}$ On such a view, names

${ }^{1}$ The avowed aim of $B R$ is to develop and fill in the gaps of Kripke's discussion of the semantics of names in Naming and Necessity. Whether it is indeed a development and extension of Kripke's semantic theory for proper names is, certainly, an important question, for it is not clear that Kripke 
have as their meanings their referents and propositions are not made up of Fregean senses, but rather of references structured in a certain way. ${ }^{2}$ Thus, on this view, (1) and (2) express the same proposition, given that (3) is true.

(1) Hesperus is visible in the evening.

(2) Phosphorus is visible in the evening.

(3) Hesperus is Phosphorus.

Two of the Fregean challenges to such Millian-Russellian accounts have to do with the prima facie difference in cognitive value between (3) and (4), and a potential difference in truth-value between (5) and (6).

(4) Hesperus is Hesperus.

(5) Peter believes that Hesperus is visible in the evening.

(6) Peter believes that Phosphorus is visible in the evening.

(3) and (4) appear to express propositions whose conditions for knowledge are different: whilst (3) appears to be a posteriori, (4) appears to be a priori. But the Millian-Russellian theorist claims that (3) and (4) express the same proposition, so it would seem

himself would have adopted a Russellian account of propositions or even a Millian theory of proper names. In Naming and Necessity, Kripke is very careful not to speak of propositions but rather of statements, and further resists saying what the semantic contribution of names is. However, Kripke's arguments for the rigidity of names and his rejection of descriptive accounts of the semantics of names do give some (if not conclusive) motivation for Millian accounts of names.

${ }^{2}$ On Soames's account, there are some names which are partially descriptive, that is, names which besides their referents have some descriptive content as part of their meaning. Examples of these are 'Mexico City', 'Mount Everest', 'The Eiffel Tower', with which the properties of being, respectively, a city, a mountain, and a tower are associated. (See BR, pp. 50-54 and chapter 5.) Furthermore, Soames leaves open the possibility that ordinary names have as their semantic content not only their referent but also some extremely general sortal. (See BR, pp. 64, 341 (footnote 2) and 362 (footnote 12).) As he does, I ignore this possibility in the main text. 
that she must explain why they appear to differ in cognitive value.

Related to this epistemological challenge is that concerning the behaviour of proper names in propositional attitude reports such as (5) and (6). Whilst (5) may be true, (6) may be false, for although (3) is true, Peter may be ignorant of this. ${ }^{3}$ The claim here is that although 'Hesperus' and 'Phosphorus' are coreferential terms they cannot be substituted salva veritate for one another in propositional attitude reports.

Many semanticists now challenge the epistemological claim that true sentences of the form $\boldsymbol{a}=\boldsymbol{a}$ do universally differ in cognitive value from sentences of the form $\boldsymbol{a}=\boldsymbol{b}$, mostly due to Kripke's “A Puzzle About Belief” (1976). There Kripke presented cases of rational and competent speakers who do not know that instances of $\boldsymbol{a}=\boldsymbol{a}$ in the language in which they are competent are true. One such case exploits the known ambiguity of names, where a subject is ignorant of the fact that Paderewski, the musician, is Paderewski, the politician. For her, coming to know that Paderewski is Paderewski is true, where the first use of the name is associated with the description of being a musician and the second with that of being a politician, will be informative. Given this, many theorists do not see an obligation to give a semantic account of the seeming difference between (3) and (4). The situation with attitude reports is different, however. Most admit that there is something that needs to be explained here. And many attempt to explain failures of substitution in terms of the semantics of propositional attitude reports, in particular of the objects of such reports. Some such explanations could, in principle, be adopted by Millian-Russellian theorists. Examples include amalgam views and the hidden indexical view. According to the former, the objects of attitude reports are amalgams of structured syntactic objects and their semantic values or references (Richard 1990, and Larson and Ludlow

\footnotetext{
${ }^{3}$ For the sake of simplicity, I shall restrict my claims and arguments to the case of belief, but it should be assumed that they cover other kinds of propositional attitude attributions.
} 
1993). According to the latter, belief is a three place relation between a subject, a Russellian proposition and a way of thinking of that proposition, where attitude reports involve a hidden unarticulated indexical element which refers to the way of thinking of the proposition (Schiffer 1979, Crimmins 1992).

There is a further approach to the failure of substitutivity, famously articulated by Salmon (1986), which accounts for the appearance of such failures of substitution in pragmatic and not semantic terms. According to Salmon, although belief is a three place relation between a subject, a Russellian proposition and a way of taking that proposition, there is nothing in an attitude report which refers to or specifies the way of taking the proposition. On his view, when I utter (5) I am saying something that is literally and semantically equivalent to (6), contrary to our intuitions regarding the failure of substitutivity; and the way of taking a proposition (which Salmon takes to be present always in a subject's believing a proposition) does not make it into the semantics of the belief report. However, on Salmon's account, one may pragmatically suggest different ways of taking a proposition by using 'Phosphorus' rather than 'Hesperus' in the embedded sentence of a belief ascription. It is this to which speakers are sensitive in thinking (wrongly in Salmon's view) that there are failures of substitutivity.

Soames adopts a similar approach to that of Salmon. His proposal is also to challenge the initial claim and related intuition that we cannot make substitutions of coreferring terms salva veritate in embedded clauses of attitude ascriptions. His view is that we can make such substitutions and that, contrary to all initial appearances, we in fact semantically express the same proposition when we assert (5) as when we assert (6). In both cases, we semantically express the proposition that Peter stands in a belief-relation to the singular Russellian proposition which has as its constituents the object Venus and the property of being visible in the evening. Soames proposes that the difference between (5) and (6) is not one to do with the semantics of such 
sentences, but rather with the extra-semantic information the assertions of such sentences convey, with their pragmatics. ${ }^{4}$

One of the primary differences between Salmon and Soames is that the latter does not commit himself to the existence of any modes or ways of taking propositions, nor to the particular nature of beliefs or any other psychological attitudes. This does appear prima facie to be an advantage of his account. If we are able to give an account of propositional attitude reports that does not commit us to specific views of the nature of propositional attitudes themselves, then we should prefer it for it will not come under attack when theories about the nature of attitudes come under attack. Whether we can indeed separate these two types of accounts is something I shall return to presently.

My main aim in this paper is to argue against Soames's account in $B R$ of the semantics and pragmatics of propositional attitude reports. In particular, I shall argue that there are reasons based on considerations from semantic competence found in $B R$ itself that count against his proposal. I begin by presenting Soames's theory of the semantics of propositional attitude reports and their pragmatics. In section 2, I consider different necessary conditions on the semantic content of sentences uttered assertively ${ }^{5}$ proposed by Soames. Of the two more inclusive and alternative conditions put forward by him, I argue (i) that depending on which we consider we may get different results for the semantic contribution of certain phrases, and (ii) that one of these constraints should be favoured for it is more general, informative and accurate than the other. In section 3, I defend the claim that failure of substitutivity is an essential

\footnotetext{
${ }^{4}$ It is interesting to note that Soames never explicitly speaks of the pragmatics of uttered sentences, but rather of the non-semantic or extra-semantic information conveyed or imparted with them. I am not sure whether there is a deep reason for this, but the accounts he gives of how such information gets to be conveyed or imparted do relate to topics of pragmatic theories, specifically, to speech act theories and to theories of communication. Hence, I see no harm in using 'pragmatic' to characterize such non-semantic or extrasemantic information, or even his own account of failures of substitutivity in ascriptions of propositional attitudes.

${ }^{5}$ When speaking of utterances I shall hereafter mean utterances with assertoric force.
} 
component of our competence conditions for propositional attitude predicates. I conclude by arguing that whilst Soames's account of the epistemological difference between (3) and (4) is most probably correct, a Millian-Russellian would do well to go back to the drawing board for an account of propositional attitude reports. ${ }^{6}$

\section{A Pragmatic Approach to Attitudes}

On Soames's view, upon assertively uttering a sentence, a speaker may be doing more than just asserting the semantic content of that sentence, even when she is speaking literally. Not only may she be conversationally implicating, suggesting or implying other propositions, but she may also be asserting other propositions. For example, if someone asks me if I have finished marking exams and I reply

(7) I handed them in last Tuesday,

I shall be taken to be asserting not only the proposition $p^{\prime}$ but also the proposition $p^{\prime \prime}$, where

$p^{\prime}=$ the proposition that Maite handed in the exam papers the Tuesday previous to $t$,

and

$p^{\prime \prime}=$ the proposition that Maite has finished marking the exams at $t$.

$p^{\prime}$ is the semantic content expressed by my assertively uttering (7), but I have further asserted $p^{\prime \prime}$.

According to Soames, whether a proposition is asserted by a speaker depends on the speaker's intentions and the background assumptions made and shared by conversational participants. A proposition is asserted by a speaker only if it is a proposition

${ }^{6}$ I shall mainly concentrate on de dicto attributions, leaving out discussions of de re attitude reports, for the claim of failures of substitution has to do with the former and not with the latter. 
which the speaker intends to convey by assertively uttering the relevant sentence in the right conversational situations with a commitment to that proposition. The nature of this commitment is such that the speaker endorses the proposition as something to be accepted by other conversational participants, she is responsible to defend it and she is accountable if it turns out to be false. ${ }^{7}$ In the case of my utterance of (7), I certainly had the intention of conveying $p^{\prime \prime}$ and was committed to it for upon uttering (7) I intended my audience to come to believe $p^{\prime \prime}$ (as well as $p^{\prime}$ ) and I would be responsible for defending $p^{\prime \prime}$ were someone to challenge its truth. My intention of conveying $p^{\prime \prime}$, moreover, is one whose existence and success depends on background assumptions in the conversational situation. For example, the assumption that handing in exam papers is usually done after marking exams plays an important part in my having asserted $p^{\prime \prime}$. I believe that my audience believes that handing in exam papers is usually done after marking exams, I further believe that my audience knows that I too believe that handing in exam papers usually happens after marking exams and that they know that I have these beliefs about them. These beliefs about the background assumption and my audience give me reason to think that when I utter (7) my audience will take me to be committed to $p^{\prime \prime}$, and hence these beliefs motivate my intention to assert and convey $p^{\prime \prime}$ by uttering (7).

My success or failure in conveying what I intend to assert depends, amongst other things, on whether the audience infers $p^{\prime \prime}$ in light of the assumption I make and as I intend them to. The assumptions that are operating in the background as well as my intentions must be mutually known to us. That is, my intentions and assumptions must be such that I believe the audience can recognize that I have those intentions and I am making the assumptions in question, my audience believes that I have that belief, I recognize that the audience has that

${ }^{7}$ For Soames, cases of conversational implicature are ones in which a speaker merely conveys or imparts a proposition, but are not cases in which a speaker asserts that proposition. This is because, in cases of merely conveying a proposition, the speaker is not committed to it in the same way as he is committed to it when she is asserting it. See $B R$, pp. 84-86. 
latter belief, and so on. Furthermore, the audience must ideally be able to infer $p^{\prime \prime}$ given this mutual knowledge. ${ }^{8}$ Of course, not every inferable proposition counts as being asserted. The inference in question would have to be such that it is mutually known by speaker and hearers that it is a "potentially direct, immediate and relevant inference" ${ }^{\prime 9}$ in the conversation. That is, the speaker believes it would potentially be direct, immediate and relevant to all conversational participants, the audience recognizes that the speaker has this belief, and the speaker knows that the audience can recognize this, and so on. Given the background assumptions upon my uttering (7), I take $p^{\prime \prime}$ to be a direct, immediate and relevant inference in the conversation which my audience can recognize to be such. ${ }^{10}$ If it is the case that my audience and I mutually know this about $p^{\prime \prime}$, then I will have succeeded in communicating $p^{\prime \prime}$ by assertively uttering (7).

Just as one can assertively utter a sentence like (7) with its literal meaning to communicate a further proposition which is not the semantic content expressed by the utterance of (7) -indeed, where one's primary intention is to convey a proposition $p$, where $p$ is not the semantic content of the uttered (7) - , one can do the same with sentences like (1)-(4) and with propositional attitude reports like (5) and (6). Assuming that the Millian-Russellian view on (1)-(4) is right, then these sentences will have as their semantic content propositions which may be represented thus:

$\left(1^{\prime}\right) \quad\langle v, E>$

$\left(2^{\prime}\right)<v, E>$

${ }^{8}$ I say 'ideally' for it does not actually have to be the case that every audience makes such an inference. Rather it only has to be the case that a rational reconstruction of the communicative event includes such an inference.

${ }^{9}$ See $B R$, p. 79.

${ }^{10} \mathrm{I}$ am leaving out of this discussion some details of Soames's account, amongst these the issue of what and how much gets to be asserted by a speaker. According to him, in many cases there will be a range of propositions that are candidates for being asserted by a speaker's assertive utterance of a sentence, but it will be indeterminate precisely which of these are thus asserted, though it will be determinate that the speaker has asserted more than the semantic content of the sentence (in a context). See $B R$, pp. 81-82. 
$\left(4^{\prime}\right) \quad<<v, v>,=>$,

where $v$ is Venus, $E$ is the (complex) property of being visible in the evening, and ' $=$ ' stands for the relation of identity. There will be no semantic difference between (1) and (2) nor between (3) and (4). But this does not entail that speakers will not make different assertions with an assertive utterance of these sentences, assertions that go beyond their semantic content. Indeed, it may well be that they will most commonly do so, for upon assertively uttering (3) a speaker will typically be wanting to assert and communicate something informative and different from his assertively uttering (4). ${ }^{11}$ Upon uttering (3) a speaker will typically be asserting not only $\left(3^{\prime}\right)$ but may also be asserting descriptive propositions, some of which may in fact be informative to her audience. Upon assertively uttering (3), the speaker may be asserting, for example, the propositions semantically expressed by (8) and/or (9).

(8) The astronomical object visible in the evenings, Hesperus, is the astronomical object visible in the mornings, Phosphorus.

(9) The second-closest planet to the sun, Hesperus, is the astronomical object seen by us last night, Phosphorus.

Whether any such descriptive propositions are asserted and if so, which are asserted by an utterance of (3), depends on the speaker's intentions and background assumptions in the conversational situation. But what is clear is that neither (8) or (9) semantically express the same proposition as (3).

Something similar happens with assertive utterances of attitude sentences. Sentences like (5) and (6) may also be used in different conversational situations to assert something that goes beyond their semantic content. And according to Soames,

${ }^{11}$ I say 'typically' because of Kripke's cases in which a hearer may find it informative to come to know that the sentence Paderewski is Paderewski is true. 
it is this fact that may be used in explaining why there is an appearance of failures of substitutivity in them.

On Soames's account, a propositional attitude report semantically expresses a proposition whose constituents are an agent, an attitude relation (e.g. the belief, the desire or the saying relation), and a Russellian proposition. Hence, there is to be no objection to substituting coreferential names within embedded clauses of propositional attitude reports. On this account, substituting 'Phosphorus' for 'Hesperus' in (5) (or vice versa in (6)) will not affect the truth-value of these reports. Given that the embedded sentences in (5) and (6) are (1) and (2), respectively, and that these express the same proposition (viz. $\left(1^{\prime}\right)$ or $\left.\left(2^{\prime}\right)\right)$, the object of the attitude predicate in (5) and (6) will be the same. Furthermore, given that the agent and the attitude predicate are the same in (5) and (6), (5) and (6) will semantically express the same proposition, viz. one that has Peter as the agent, a beliefrelation and the Russellian proposition $\left(1^{\prime}\right)$ as the object of the belief-relation. Thus replacing 'Hesperus' for 'Phosphorus' in (5) or vice versa in (6) cannot affect their truth-value.

When someone asserts (5), she is semantically asserting the same proposition as she would be asserting with (6), but she is also —on Soames's account - asserting and conveying different descriptive propositions, perhaps those semantically expressed by (10) upon uttering (5) and (11) upon uttering (6).

(10) Peter believes that the second-closest planet to the sun, Hesperus, is visible in the evening.

(11) Peter believes that the planet much talked of by Frege, Phosphorus, is visible in the evening.

Again, whether any other propositions are also asserted by utterances of (5) and (6), and if so, which, depends on the background assumptions in the conversational situation and the speaker's intentions. Suppose the utterer of (5) and his audience associate the descriptions 'the second-closest planet to the sun' and 'the astronomical object most mentioned by philosophers of language' with 'Hesperus', and that it is a matter of mutual 
knowledge amongst them that this is so. Suppose further that the conversational participants have reason to think that Peter only associates the first description with 'Hesperus', and that this is a matter of mutual knowledge amongst them. Then upon assertively uttering (5), the speaker will not be committing herself (nor will she be taken to be committed) to the proposition that Peter believes that the astronomical object most mentioned by philosophers of language is visible in the evening, and so will not be asserting that proposition. ${ }^{12}$ But given the common background information upon making her utterance she will be taken to be asserting the proposition semantically expressed by (11).

When rational and competent speakers of the language judge that there is a difference in truth-value between (5) and (6), according to Soames, they are being sensitive not to the semantic content of (5) and (6), but rather to the pragmatically conveyed propositions that arise from assertively uttering (5) and (6). Suppose that, in the conversational situation in which the speaker utters (5), it is a matter of mutual knowledge that Peter associates different descriptions with 'Hesperus' from those he associates with 'Phosphorus' (the reason why he rejects (3)), and that he associates 'the second-closest planet to the sun' with the former and 'the planet much talked of by Frege' with the latter. Then upon uttering (5), the speaker will be asserting $\left(3^{\prime}\right)$ and the proposition semantically expressed by (11). Were we to substitute 'Phosphorus' for 'Hesperus' in (5) we would obtain (6), an utterance of which will be taken to assert, besides $\left(3^{\prime}\right)$, the proposition semantically expressed by (11) and not that expressed by (10). And whilst (10) may be true, (11) may not be true. Thus, on this account our impression that there are failures of substitution has nothing to do with the propositions semantically expressed by utterances of attitude ascriptions $\left(\left(3^{\prime}\right)\right.$ in our example), but rather with the propositions that are pragmatically asserted by assertive utterances of such ascriptions.

The success of this account depends upon at least two things: on whether this way of explaining the failures of substitutiv-

${ }^{12}$ See especially BR, pp. 221-224. 
ity or the appearance thereof is sufficiently convincing and on whether Soames's account of the semantic content of propositional attitude reports is correct. I shall turn to these issues in the next two sections.

\section{Semantic Content}

Throughout BR Soames offers three different necessary conditions for a proposition to be the semantic content of an assertively uttered sentence rather than being just a proposition that is non-semantically or pragmatically asserted. The first necessary condition is primarily intended to cover utterances of sentences with proper names, whilst the other two are offered in order to accommodate also sentences with ambiguous expressions and indexicals.

According to the first necessary condition, the Invariants Condition ('IC' hereafter), a proposition is the semantic content of a sentence $s$ only if it is the proposition that is asserted by a speaker who assertively utters $s$ in all normal contexts; to put it bluntly, it is the proposition that is always asserted. By 'normal context' I mean here a context in which the sentence is used by competent speakers who understand the meaning of the sentence in question, and it is used by them with its literal meaning, not metaphorically, ironically or sarcastically, and in which the speaker's commitment to the proposition asserted is not defeated by some conversational implicature. ${ }^{13}$

IC. A proposition $p$ is semantically expressed by a sentence only if $p$ is included in the information a competent speaker would assert and intend to convey by an assertive utterance of $s$ in any normal context. ${ }^{14}$

${ }^{13}$ For the sake of simplicity, I use the notion of 'normal context' below to abbreviate all these features. Such usage should not be directly attributed to Soames. Also, the names I have given to the conditions are mine and not Soames's. They correspond to his $C+, C+a$ and $C+b$, respectively.

${ }^{14}$ Soames sets further conditions (which I have not included here) on whether a proposition $p$ and not $q$ is what is semantically asserted by an utterance of a sentence. These have to do with the explanatory primacy of $p$ over $q$. See $B R$, pp. 61-63, 106-107. 
IC is clearly not a suitable necessary condition for utterances of sentences with indexical elements, for the propositions that such utterances express may vary from one context of utterance to another. In order to accommodate these, Soames presents two alternative and more inclusive conditions. These are meant to deliver the same results given certain assumptions about semantic competence. Both conditions introduce a relativization to contexts of utterance, and both may be used also for identifying the semantic content of sentences containing names, so that IC may be given up in favour of either of them. But they differ in other ways. The Referents Condition assumes, as part of the contexts across which the same proposition is asserted, that the indexicals have the same reference in them as they do in the original context of utterance. The Competence Condition instead focuses on what is determined by the semantic conventions or competence conditions for the use of a phrase.

RC. A proposition $p$ is semantically expressed by a sentence $s$ relative to a context of utterance $C$ only if $p$ is information a competent speaker would assert and intend to convey by an assertive utterance of $s$ in any normal context $C^{\prime}$ in which (i) all indexicals in $s$ have the same referents in $C^{\prime}$ that they do in $C$, and (ii) all ambiguities in $s$ are resolved the same way in $C^{\prime}$ as in $C$.

CC. A proposition $p$ is semantically expressed by a sentence $s$ relative to a context of utterance $C$ in which $s$ is assertively uttered with its normal literal meaning only if the assertion of $p$ is determined by the application of the semantic conventions (competence conditions) that must be grasped by any speaker who understands $s$ as it is used in $C$ - provided that $C$ is a normal context.

$\mathrm{RC}$ and $\mathrm{CC}$ are supposed to deliver the same results for assertive utterances of indexical sentences in all normal contexts in which they are used with their literal meanings, since the only propositions asserted by utterances of $s$ in all normal contexts which satisfy RCi and RCii are propositions whose assertion in 
$C$ is determined by the application of the semantic conventions or semantic competence conditions associated with $s$ as used in that context. Consider my assertive utterance of (7) again. Given that I utter (7), the proposition semantically expressed by it, given $\mathrm{RC}$, is just $p^{\prime}$ above, for the resolution of the referents of indexicals will have it that I am the utterer and hence that I figure in the proposition semantically expressed by (7). Such resolution depends on the semantic competence conditions for ' $I$ ', which are that it be used to refer to the utterer in a context and that its contribution to the proposition expressed by a sentence that contains it is just the referent in that context. Given these competence conditions and the context in which (7) is uttered, CC has it also that the proposition that is semantically expressed by my assertive utterance of (7) is $p^{\prime}$.

But the fact that RC and CC yield the same results for indexicals, and even for proper names and ambiguous expressions, does not entail that they yield the same results every time. Consider a sentence $s^{\prime}$ containing a phrase $e$ which is not ambiguous, indexical or a proper name, which is not semantically redundant, and which occurs in a sentence $s^{\prime}$ uttered in a normal context $c^{\prime}$. Given RC, the semantic contribution of $e$, hence, the proposition expressed semantically by the utterance of $s^{\prime}$ in $c^{\prime}$, is just its contribution in all normal contexts in which $s^{\prime}$ is used and in which all ambiguities and indexicals have the same resolution or reference. Suppose that $e$ is a vague phrase (be it a vague term like 'Mount Everest' or a vague predicate like 'is tall'). It is not clear that the semantic propositional contribution of vague phrases will be the same in every normal context. Nor is it clear that vague phrases are indexical or ambiguous. ${ }^{15}$ But then RC will not be of help in determining the semantic propo-

\footnotetext{
${ }^{15}$ In fact, I think they are not. 'Mount Everest' and 'is tall' are vague but not indexical, for there is no single feature of a context of utterance which must vary for there to be a variation in reference. ' $\mathrm{I}$ ', 'now' and even demonstratives like 'that' are such that for their utterances to vary in reference it must be the case that the utterer be different, the time of utterance be different or the salient object be different. Nor are vague phrases ambiguous in the way that 'bank' or 'Peter' are, i.e. such that their different uses entail a radical difference in meaning.
} 
sitional contribution of vague phrases. In contrast, CC gives us a principled way of determining this contribution. What we need to do is look at the semantic competence conditions concerning $e$ and we shall have a way of determining what contribution they make to the proposition expressed by the utterance of $s^{\prime}$ in $c^{\prime} .{ }^{16}$ This, of course, does not entail that these competence conditions are not themselves difficult to determine. In fact, many of them are, and that is in fact why we engage in the discussion of the semantics of phrases. For our present purposes, it suffices that we have a wedge between RC and CC, and that there is a sense in which CC is more general and overarching than $\mathrm{RC}$ (and IC). Furthermore, by specifying that what determines the semantic content of an uttered sentence are the semantic competence conditions associated with that sentence, we also have a more accurate and informative necessary condition for what is semantically expressed. It is for these reasons that we should prefer CC over RC (and IC).

Upon discussing the semantics of propositional attitude reports, Soames suggests that IC should be applied here, so that the semantic content of a report be just whatever proposition is asserted in every normal context in which it is assertively uttered. And the sorts of propositions that are thus uttered in every normal context are, according to Soames, just the ones he predicts, viz. ones that contain an agent, an attitude relation and a Russellian proposition. But given that CC is more general and overarching than IC, we should obtain the same result were Soames to be right about the semantics of propositional attitude reports. The problem is just that we do not.

\section{Competence Conditions for Propositional Attitude Predicates}

According to Soames, the constraints on semantic content show that, in the case of propositional attitude reports, what gets semantically expressed is a relation which an individual has to

\footnotetext{
${ }^{16}$ Vague phrases may be context-dependent in a way that differs from indexicals. Identifying the semantic competence conditions for such phrases should tell us how they are.
} 
a Russellian proposition. His reasoning is as follows. Take an atomic sentence like ( 1 ) which contains a name and a predicate, where the name 'Hesperus' refers to $v$ and the predicate expresses $E$, viz. the property of being visible in the evening. The proposition semantically expressed by such a sentence is $\langle v, E\rangle$, given IC and Kripkean arguments against descriptive accounts of names. ${ }^{17}$ Suppose now that the predicate is a complex predicate like Peter believes that $x$ is visible in the evening. Then, the proposition expressed will be a Russellian proposition which involves Venus or $v$ and the property $\lambda x$ (Peter believes that $x$ is visible in the evening). ${ }^{18}$ Take the construction $\boldsymbol{A}$ believes that $\boldsymbol{y}$ is $\boldsymbol{\varphi}$ to be expressing a relation between a subject $A$ and the proposition expressed by $\boldsymbol{y}$ is $\boldsymbol{\varphi}$, and the proposition expressed by an instance of the latter, say $y$ is visible in the evening, to be relative to an assignment $v$ of $y$. We then obtain that (5) just semantically expresses the proposition that Peter stands in a belief-relation to the Russellian proposition that $v$ is visible in the evenings. That constructions such as (5) may be used to assert further propositions such as (10) will not matter to what is semantically expressed.

The reasoning as it stands is impeccable if one does not focus on the competence conditions or semantic conventions associated with the predicates of propositional attitudes. But once one starts considering such competence conditions, then it is clear that a straightforward reasoning from atomic predicates

${ }^{17}$ See especially $B R$, pp. 63-67. There Soames applies IC to the case of utterances of sentences with names, whilst assuming in the background that Kripke's arguments against descriptive accounts of names are sound. (See $B R$, chapter 2.) Presumably, one could argue that one of the propositions that is asserted and intended to be conveyed in every normal context in which (1) is uttered is the metalinguistic proposition semantically expressed by The referent of 'Hesperus' is visible in the evening. Kripkean modal arguments against descriptive accounts of names rule out propositions of this sort as candidates for what is semantically expressed by utterances of sentences with names.

${ }^{18} \mathrm{We}$ here have the essentials of an argument for the claim that all de dicto propositional attitude attributions involving names in their 'that'-clauses are de re attributions. 
to the objects of attitude verbs cannot be extracted. What are such competence conditions?

Speakers who are competent in the use of propositional attitude predicates know that these are relational, relating agents to objects of a different sort, objects which are referred to or expressed by sentences in the 'that'-clauses of attitude ascriptions. The nature of such objects is not straightforwardly obtained from the competence conditions of such predicates, and it is precisely what is at issue here. However, there are certain conditions which a competent speaker must satisfy in order to be said to understand a sentence with a propositional attitude phrase. She must know that such phrases are used to make propositional attitude attributions, and that such reports can and often are themselves used in explaining the actions and mental states of the agents to whom the attribution is made. These explanations may include short explanations or rationalizations of actions or mental states given in every day life such as (12)-(15), or more complex fully fledged explanations which cite ceteris paribus laws or generalizations, and sets of beliefs, desires, etc.

(12) I stopped looking for the shopper who was spilling the sugar throughout the supermarket because I realized that I was the one spilling the sugar throughout the supermarket.

(13) Lois Lane did not go with Clark Kent because she believed that Clark Kent was not Superman.

(14) Although Peter wanted to see Hesperus, he did not wake up early in the morning to see it, because he believed that Hesperus is not visible in the mornings.

(15) Paul came to believe that Carl Hempel wrote Aspects of Scientific Explanation because his supervisor told him that he did.

For a competent speaker of the language to use propositional attitude sentences in explanations of actions or mental states, she 
must be sensitive to the changes that can be brought about by allowing for substitutions of coreferential terms such as 'Clark Kent' for 'Superman' in the embedded clause in (13). The speaker competent in attitude reports must know that substituting one name for the other just loses the explanatory power of the belief report in (13). Similarly, substituting 'Maite' in the 'that'-clause in (12) when uttered by me for 'I' as in (12') would make the attitude report lose its explanatory power. But more than this. Assuming that I am amnesiac and I do not know that my name is 'Maite', $\left(12^{\prime}\right)$ would be false whereas (12) would be true. $^{19}$

$\left(12^{\prime}\right)$ I stopped looking for the shopper who was spilling the sugar throughout the supermarket because I realized that Maite was the one spilling the sugar throughout the supermarket.

There are then two sources to the claim that propositional attitude reports do not guarantee successful substitutions of coreferential terms. The first is the lack of guarantee in truth-value, and the other is the lack of guarantee of preservation of explanatory power. It seems then that what is clear about propositional attitude predicates to all rational and competent speakers is that there is failure of substitutivity of coreferential or, more generally, coextensional, expressions occurring in embedded clauses of attitude reports. Thus, if anything seems to be an essential part of a speaker's semantic competence with attitude predicates, it is the failure of substitutivity. It would seem then that no matter what account we favour of the semantics of propositional attitude reports, what they must do is allow for accounts of failure of substitutivity. If this is so, then clearly the account offered by Soames of propositional attitude reports in which such competence conditions are not captured fails by Soames's own CC.

The strength of this objection should not be underestimated. The criteria that Soames sets for the semantic content of an

${ }^{19}$ The similarities with Perry's case for indispensability of indexicals should be obvious. See Perry 1979. 
assertively uttered sentence are part of what drives him into the accounts he offers of proper names, partially descriptive proper names ${ }^{20}$ and indexicals. If such criteria are to be used in obtaining principled accounts of what qualifies as the semantic contributions of these phrases to sentences assertively uttered, then the same ought to be true of predicate phrases involving propositional attitude verbs.

There are two possible rejoinders that Soames could offer. The first would be to say that the point has simply been missed. He may claim that what he has been doing is precisely to say why such failures of substitutivity should not be taken as part of the competence conditions associated with the use of propositional attitude predicates. But at most what Soames offers is an account of how one could explain the appearance of such failures of substitutivity if we do not assume that they are part of the competence conditions, and not an account of why they are not to be taken as such. For instance, we are given no reasons for saying that there is some illusion in thinking that they are part of the competence conditions, nor are we given any account of why such intuitions regarding failures of substitutivity are so persistent and widespread. ${ }^{21}$ By contrast, assuming that the appreciation of failures of substitutivity is part of the semantic competence conditions for propositional attitude phrases would explain why they are so persistent and widespread.

To bring the point home, consider a subject who is not only a fully rational and competent speaker of English but is also an expert in making distinctions between what belongs to semantics and what to pragmatics, using (amongst other theoretical resources) Soames's criteria for propositions that are semantically expressed or asserted and those that are just pragmatically asserted. In referential uses of definite descriptions, for example, she clearly distinguishes the pragmatically conveyed sin-

${ }^{20}$ See footnote 2 above.

${ }^{21}$ Soames seems to acknowledge that the persistence and ubiquitousness of intuitions of failures of substitutivity need to be explained $(B R$, p. 142), but nowhere does he provide such an explanation. 
gular proposition from the semantically expressed descriptive proposition. Suppose further that she knows all the relevant facts pertaining to Peter's state of belief and the identity of Hesperus. She knows that Peter does not know that Hesperus is Phosphorus, that he denies (3), and she knows that (3) and (16) express true propositions.

(16) Peter believes that Hesperus is Hesperus.

If Soames's story were right, given that she is an expert on the semantics-pragmatics divide, we would expect her to say that one may substitute 'Phosphorus' for 'Hesperus' in (16) to obtain a true (17).

(17) Peter believes that Hesperus is Phosphorus.

The problem is that not only would she not do so, but we would expect her not to do so. To bring the point home think again of what would happen to the explanatory power of propositional attitude reports in (13)-(15) if such substitutions were allowed. We would expect her to be sensitive to the loss of such explanatory power. We would also not only expect the expert not to make such substitutions but also not to allow them. If there is a mistake that the expert and competent speakers are making in judging that there are failures of substitutivity, it seems to be of a different sort, and Soames still owes us an explanation of what that may be.

But perhaps even the expert on the semantics-pragmatics divide is mistaken. Soames does provide an argument for not always taking judgements of speakers at face value. This argument concerns the judgements speakers may make about whether sentences like (3) and (4), for example, have the same meaning. He argues that speakers usually do not distinguish what is semantically conveyed or asserted by an utterance of a sentence from what is pragmatically conveyed or asserted. Rather - he says — in making their judgements about meaning, speakers only consider what the sentences are typically used to convey or else focus on cases in which the information conveyed 
might be different. ${ }^{22}$ Soames may well be right in being sceptical about the judgements speakers make about the sameness and difference in meaning, but our expert is not open to this objection for she is an expert at making such a distinction. Furthermore, the case we have presented here does not even concern judgements about meaning. The judgements speakers make with propositional attitude attributions have to do with their intuitions concerning the truth-value of the uttered sentences, not with whether they share the same meaning or not. Soames is certainly sensitive to this difference, but he seems to think that the reasoning about speakers' intuitions and judgements about meaning is easily extended to that of speakers' intuitions and judgements about truth-value. He writes:

the fact that speakers are prone to confuse the semantic content of a sentence, its meaning in the language, with what a speaker uses it to assert in a particular context just shows that being a competent speaker requires neither having a theoretical understanding of what semantic content is, nor the systematic ability to recognize when two sentences that one understands have the same semantic content.

The same points hold regarding [(5) and (6)], plus the additional fact that substitution of one coreferential name for another in an attitude ascription may seem to have the capacity to change truth-values in attitude ascriptions in ways that are not possible in many simple sentences. ( $B R$, pp. 228-229)

If judgements and intuitions of speakers about the truthvalues of (5) and (6) were to depend upon judgements and intuitions about their semantic content then Soames would be right. But it just is not clear that they are thus dependent. Rather it seems to be the other way around. A speaker's judging two (utterances of) sentences as having different truth-values would give her some reason to think that they differed in meaning, for although difference in meaning does not entail difference in truth-value, difference in truth-value does entail a difference in meaning.

${ }^{22}$ See BR, pp. 68-69. 
The second rejoinder which Soames could offer is just to claim that he is providing a revisionist account of propositional attitude reports, but that we are forced to it either by the failure of other attempts within a Millian-Russellian framework of accounting for them or by the fact that we cannot consistently account for other features or phenomena that arise from propositional attitude predicates if we accept failure of substitutivity, or both. Indeed, Soames's arguments against the theories for propositional attitude reports offered by Richard (1990) and Larson and Ludlow (1993) ${ }^{23}$ would seem to provide some motivation for his view. In addition, there do seem to be cases in which there are successes of substitution of coreferential expressions which Soames points out, and which would appear to challenge the claim of failure of substitutivity $(B R, \mathrm{pp} .166-$ 169).

Although, for reasons of space, I shall not enter here into a discussion and defence of Larson's and Ludlow's or of Richard's theories of propositional attitude reports from Soames's objections, ${ }^{24}$ two issues are worth noting. Firstly, even if Soames's objections to these theories are successful, there are alternatives to these theories which have not been considered by Soames in $B R$ and which prima facie accord well with the Millian-Russellian motivated account of names and propositions, for example, hidden indexical theories. Secondly, even if none of these accounts were to be successful, it would appear that the motivation for Soames's view would be weak if the recognition of failures of substitutivity is an essential component of our semantic competence with propositional attitude predicates. In this case, the

${ }^{23}$ See $B R$, chapter 7 .

${ }^{24}$ There are two sorts of criticisms levelled by Soames against Larson's and Ludlow's account, the interpreted logical form (or ILF) account. The first sort concerns the tie between the ILF account and the Davidsonian programme for an interpretive truth-theoretic semantics. I suspect that Larson's and Ludlow's ILF account is not tied to the Davidsonian programme in the way that leaves it open to Soames's objections (see Larson and Segal 1995). The second sort of criticism concerns cases in which there appear to be successful substitution of coreferential expressions. Some (but certainly not all) of what I say below on this matter may be seen as advancing a defence of Larson's and Ludlow's ILF account. 
motivation would be to go back to the drawing board for an account that does take into consideration the recognition of failures of substitutivity.

However, if there are cases of successful substitution of coreferential expressions, this might appear to challenge the claim that acknowledging failures of substitutivity is an essential component of our semantic competence with attitude predicates. But this is just an appearance. We should be clear about what the claim that there is a failure of substitutivity in propositional attitude reports involves. The claim is not that there can be no successful substitution of coreferential (or coextensional) expressions, but only that making such substitutions does not always preserve, or does not guarantee, the preservation of truth-value nor of explanatory power. Thus, providing examples in which such substitutions are successful does not yet count as evidence that failure of substitutivity is not part of the competence conditions for propositional attitude predicates.

To bring the point home let us consider two sorts of cases in which truth-value is preserved if substitution of coreferential terms in the 'that'-clauses is made and why such preservation does not affect the claim that semantic competence with propositional attitude predicates requires recognition of failures of substitutivity.

Take (5) and (6) again. Although (5) is not typically used interchangeably with (6), there are contexts in which it would appear that we may use it so. Suppose that it is part of our common background information that Peter believes that Hesperus is Phosphorus, i.e. that he assents to utterances of (3) and that he associates the same descriptions with one name as he does with the other. In this case, it would appear that a substitution of 'Phosphorus' for 'Hesperus' is licensed and that we could have used (5) and (6) interchangeably. The issue is whether such substitutions are licensed because of what is involved in our semantic competence with propositional attitude predicates or because of extra-semantic information. If it is not the former but the latter, then there is little reason to take these sorts of cases as favouring Soames's view. What allows for such 
substitution in this case is simply some knowledge about Peter's psychological state, which is shared by the conversational participants (for example, knowing (18)), but which is itself external to the knowledge involved in being competent in the use of propositional attitude phrases.

(18) Peter believes that Hesperus is Phosphorus.

Thus, we haven't yet a challenge to the claim that recognition of failures of substitutivity is not a part of our semantic competence with attitude predicates.

Nonetheless, there are cases in which substitution of coreferential expressions is not only successful, but also mandatory. These are cases in which indexicals occur in the embedded sentences of propositional attitude reports. ${ }^{25}$ Say I report a belief of Sarah's by uttering (19) on day 1. For me to report Sarah's belief on day 2, I cannot use (19), but may rather use (20), and on day $3(21)$.

(19) Sarah believes that Manaia will be arriving tomorrow.

(20) Sarah believes that Manaia arrives today.

(21) Sarah believes that Manaia arrived yesterday. ${ }^{26}$

Any reporter of Sarah's belief on the different days must make substitutions of one indexical for another in order to accurately report what she believes. Whether this is a threat to the claim that recognition of failures of substitutivity is part of our semantic competence with attitude predicates depends on where the source of the mandatoriness and of the guarantee of such substitution is.

Frege well noted that if I am to express the same proposition today as I did yesterday and tomorrow as I did today, then I must substitute 'today' for 'tomorrow' and 'yesterday' for

${ }^{25}$ In fact, cases of this sort are part of what motivates Soames's rejection of Larson's and Ludlow's account of propositional attitude reports. See $B R$, pp. 157-159.

${ }^{26} \mathrm{I}$ am ignoring issues of tense here. 
'today'. But this applies to all utterances of sentences containing these indexicals, not only ones that occur embedded in attitude attributions. For me to express the same proposition on day 2 as I did on day 1 in using (22), I must use (23) and, on day 3 , I must use (24).

(22) Manaia is arriving tomorrow.

(23) Manaia arrives today.

(24) Manaia arrived yesterday.

The mandatoriness of the substitution stems then from the change in the context of utterance of the sentence and the semantic rules of reference of indexicals. 'Today' refers to the day of utterance, 'tomorrow' to the day after the day of utterance and 'yesterday' to the day before the day of utterance. These rules of reference are themselves part of the semantic conventions associated with these indexicals. But more than this: the link which Frege noted between these indexicals is also part of the semantic conventions associated with them and so of our semantic competence with them. That is, knowing that in order to guarantee expressing the same proposition and, hence, to guarantee reference to the same day as the day of utterance changes, one must substitute 'today' for 'tomorrow' and 'yesterday' for 'today' on consecutive days, is part of speakers' semantic competence with these indexicals. Something similar applies to other indexicals and the substitutions we may make between them. For someone else to say the same as I said when I used ' $\mathrm{I}$ ', they must use other indexicals such as 'she' (whilst making me the more salient object) or 'you' if I am the person she is addressing.

Although the source of the mandatoriness and of the guarantee of success in substitutions stems from our semantic competence in this case, the semantic competence from which it stems is that concerning the use of indexicals, not the use of propositional attitude predicates. Thus, there is no reason yet to doubt that acknowledging failures of substitutivity is part of our semantic competence with attitude predicates. It is just that 
when it interacts with indexicals, it must accord with what is involved in our semantic competence with them.

\section{Final Remarks}

Given that propositional attitude reports have a role in the explanation of actions and other mental states, and that this role may be lost if failure of substitutivity of coreferential terms embedded in the 'that'-clauses is denied, not only should a successful account of propositional attitude reports respect failures of substitutivity, but it should also say what that explanatory role consists in. It is not clear, however, that we can give an account of this explanatory role if we do not look at what the attitude reports are reports of -more particularly, if we do not consider the way in which attitudes elicit behaviour and other mental states. Upon giving explanations of actions and other mental states that include attitude attributions, we typically purport to be giving causal explanations, but on many occasions we mean to be doing more than this. We often use them to justify or rationalize the action or mental state in question. And we do this because we take it that the attitudes themselves not only cause other attitudes and/or actions, but they also in some sense rationalize them. Thus, in order to give a proper account of propositional attitudes and how they fulfil their explanatory role, we should investigate the nature of the explanations in which they figure, and this will most likely require delving at least a little into the nature of the attitudes themselves. So although giving an account of propositional attitude reports without considering the nature of the attitudes themselves initially might have been an appealing feature of Soames's proposal, it seems unlikely that we can do so, especially if we are to explain the explanatory role of attitude reports, and hence our semantic competence with attitude predicates. ${ }^{27}$

${ }^{27}$ At this point, one may want to distinguish between different propositional attitude reports and claim that in the case of propositional attitude predicates that appeal to mental states, such as 'believes that' and 'desires that', there are other propositional attitude predicates that do not have the same explanatory role as these for which perhaps the considerations given here do not apply. 
It is worth noting what I have not done or intended to do here. First and foremost, nothing of what has been argued here challenges the general Millian-Russellian approach that Soames advocates nor in particular the arguments that he gives in favour of the Millian character of names. Names may still only contribute their referents to the propositions expressed by (utterances of) sentences containing them, and propositions are still made up of references structured in a certain way.

Secondly, nothing of what has been argued here challenges the account given by Soames of the epistemological difference between (3) and (4) nor his general approach to distinguishing amongst the propositions that are merely asserted and those that are also semantically expressed. I think Soames's account of the difference that may emerge between (3) and (4) is correct. As we learned from Kripke (1976), not every utterance of a sentence of the form $\boldsymbol{a}=\boldsymbol{a}$ is uninformative to rational and competent speakers of the language. 'Paderewski is Paderewski' may be just as informative to a rational and competent subject as 'Hesperus is Phosphorus'. The difference on when utterances of sentences are informative may be explained in terms of their pragmatics as Soames suggests, that is, in terms of the propositions which are asserted by these utterances but which are not semantically expressed by them. My claim here has been only that this approach cannot be extended to propositional attitude reports or, at least, not without further discussion of what our semantic competence with attitude predicates involves. ${ }^{28}$

These include predicates like 'says that' or 'tells that' or 'asserts that'. These typically have a role not in explaining actions or mental states, but rather constitute the explanandum in an explanation of actions. They have as their extensions the actions themselves which are caused by mental states such as belief and desire. However, even if this were so (though it is doubtful, for see (15) above), it is unclear that the considerations given here do not apply, for we would still need to explain why it is that beliefs and desires explain these actions and thus what those actions consist in.

${ }^{28}$ The final version of this paper was written whilst visiting the Department of Philosophy at the University of Auckland. I am grateful to the Department for providing an excellent environment to work in and, especially, to Justine Kingsbury and Jonathan McKeown-Green for helpful discussions and comments to an earlier version. I am also grateful to the Dirección General 


\section{REFERENCES}

Crimmins, M., 1992, Talk about Beliefs, MIT Press, Cambridge, Mass.

French, P.A., T.E. Uehling and H.K. Wettstein (eds.), 1979, Contemporary Perspectives in the Philosophy of Language, University of Minnesota Press, Minneapolis.

Kripke, S., 1976, “A Puzzle About Belief” in Margalit 1976.

—_, 1972, Naming and Necessity, Harvard University Press, Cambridge, Mass. (Reprint 1980.)

Larson, R. and P. Ludlow, 1993, "Interpreted Logical Forms", Synthese, vol. 95, no. 3 .

Larson, R. and G. Segal, 1995, Knowledge of Meaning, MIT Press, Cambridge, Mass.

Margalit, A. (ed.), 1976, Meaning and Use, Reidel, Dordrecht.

Perry, J., 1979, "The Problem of the Essential Indexical", Noûs, vol. 13 , no. 1 .

Richard, M., 1990, Propositional Attitudes, Cambridge University Press, Cambridge.

Salmon, N., 1986, Frege's Puzzle, Ridgeview, Atascadero.

Schiffer, S., 1979, "Naming and Knowing", in French et al. 1979.

Soames, S., 2002, Beyond Rigidity, Oxford University Press, Oxford.

Received July 5, 2004; accepted October 6, 2004.

de Asuntos del Personal Académico of the UNAM for the grant that allowed me to visit Auckland. 